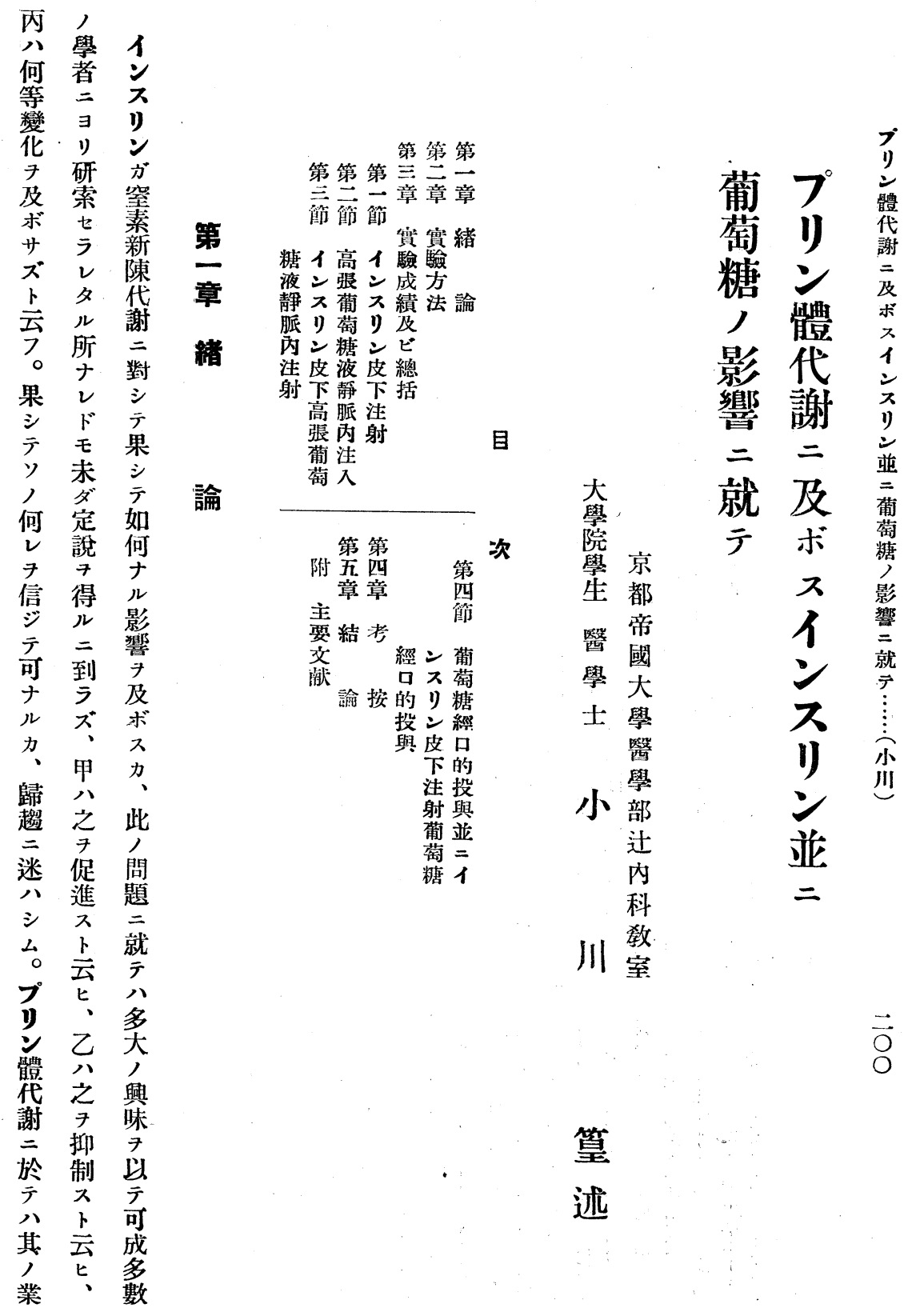




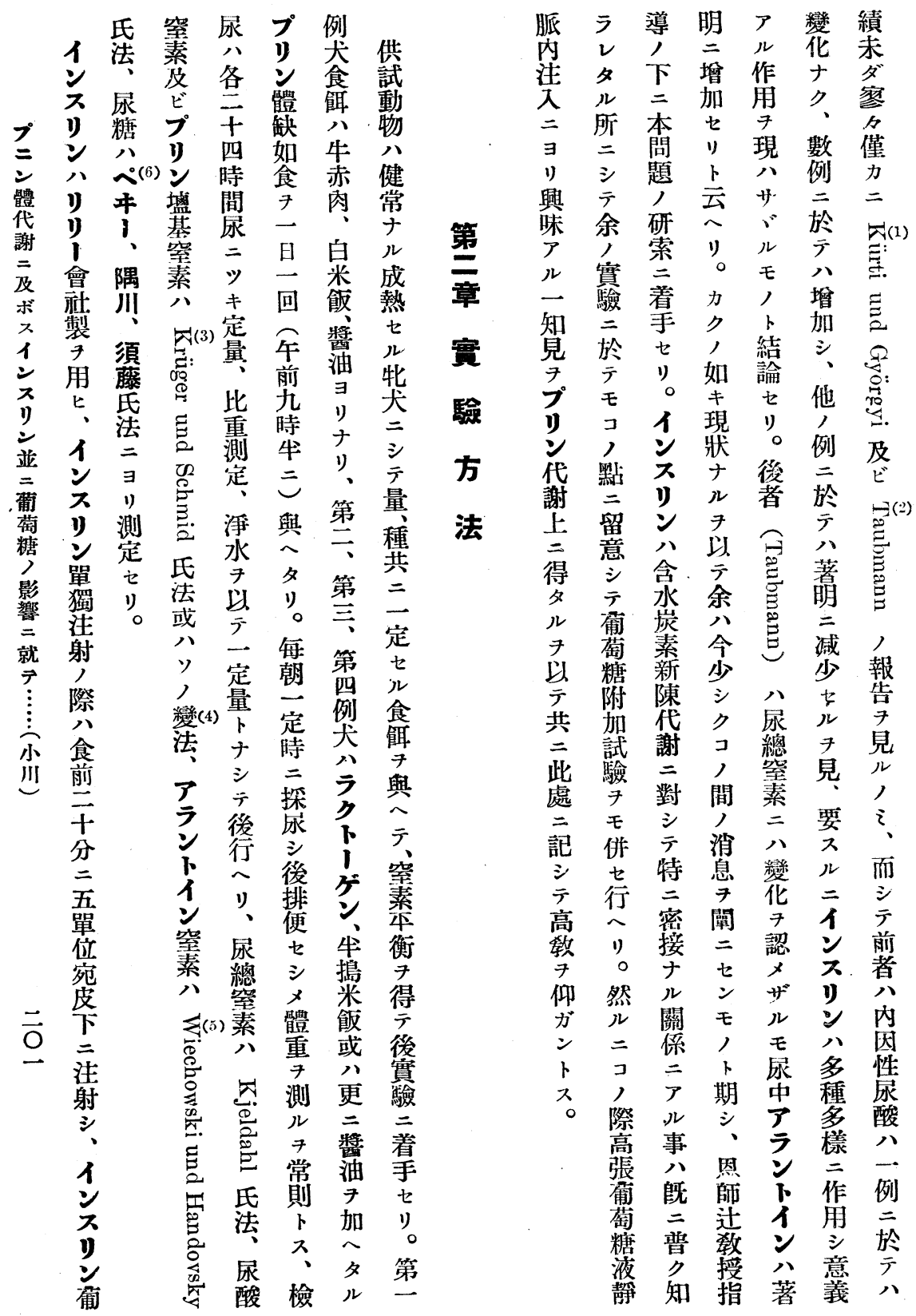




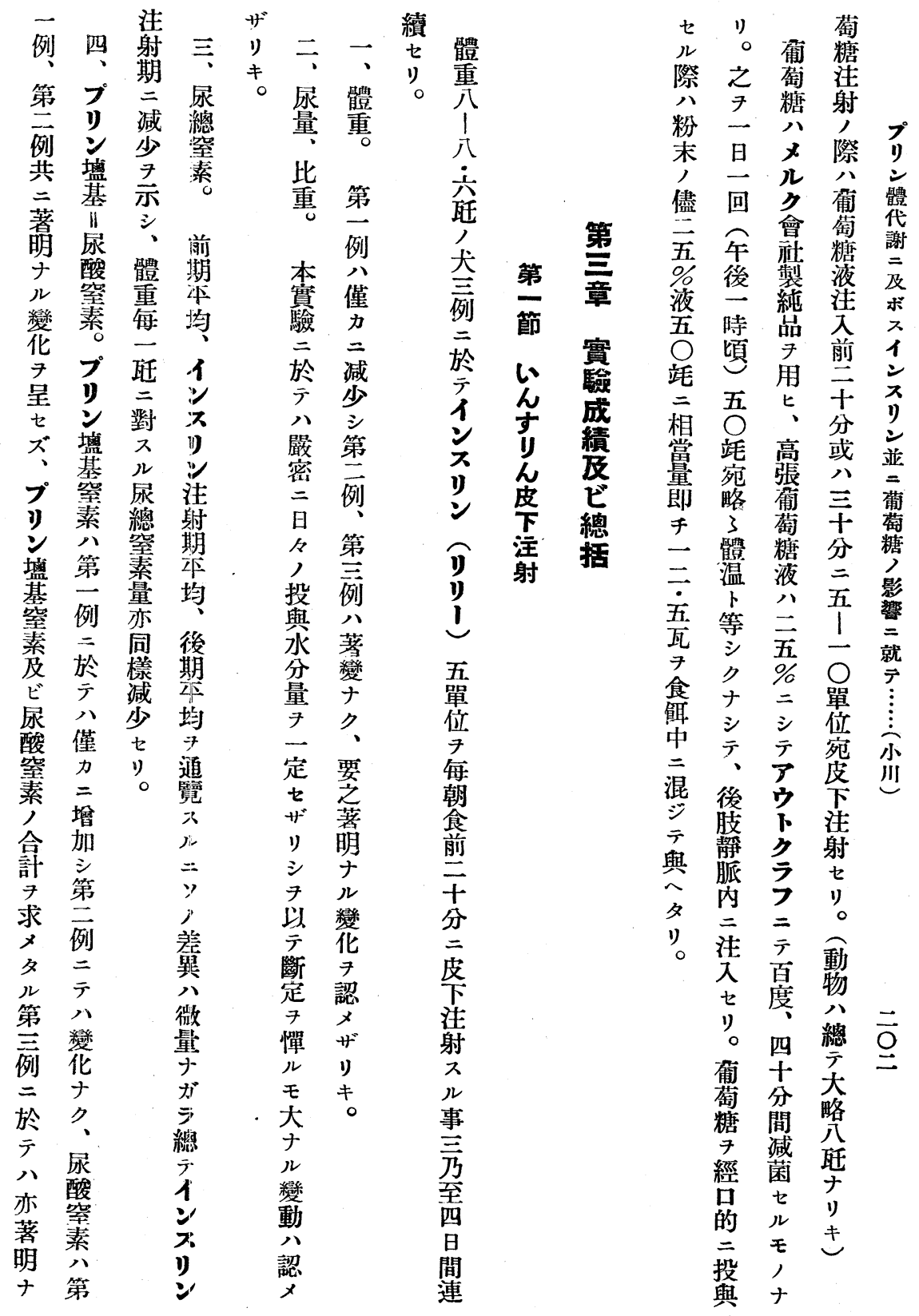




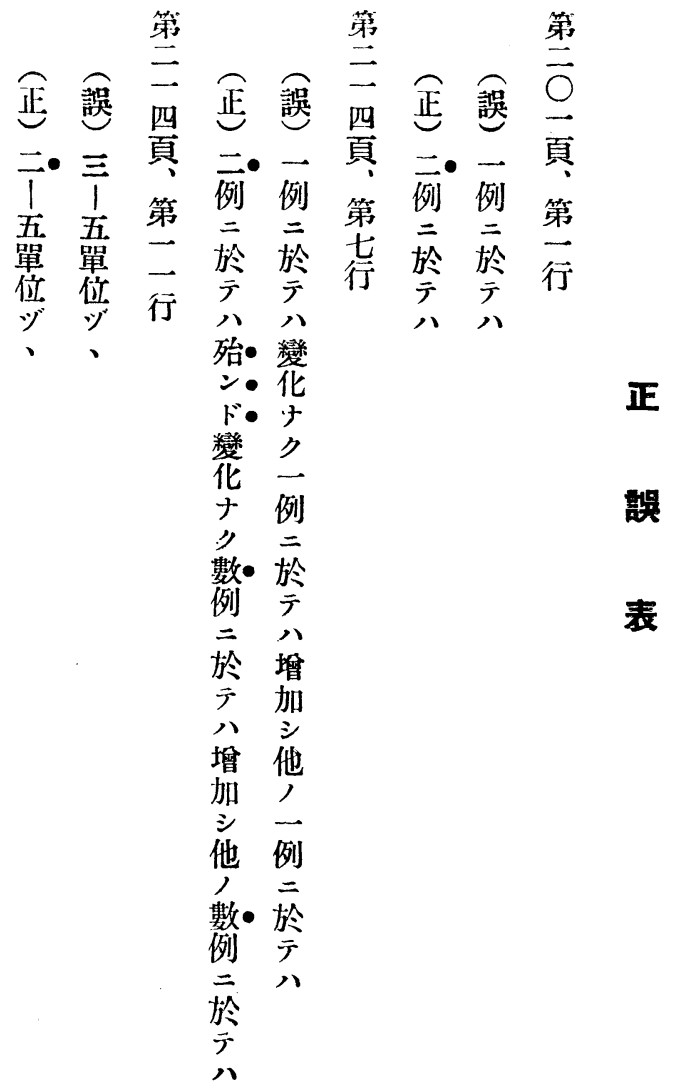




\begin{tabular}{|c|c|c|c|c|c|c|c|c|c|c|c|c|c|c|}
\hline \multirow{2}{*}{1} & \multirow{2}{*}{ 月日 } & \multirow{2}{*}{$\mid \begin{array}{l}\text { 體重 } \\
\mathrm{kg}\end{array}$} & \multirow{2}{*}{$\begin{array}{l}\text { 尿量 } \\
\text { c.c }\end{array}$} & \multirow{2}{*}{$\begin{array}{l}\text { 比重 } \\
15^{\circ} \mathrm{C}\end{array}$} & \multirow{2}{*}{$\begin{array}{c}\text { 攝取 } \\
\text { 窒素 } \\
\mathrm{g}\end{array}$} & \multicolumn{2}{|c|}{ 尿總咥素 } & \multicolumn{2}{|c|}{ 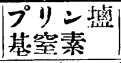 } & \multicolumn{2}{|c|}{ 永酸窒素 } & \multicolumn{2}{|c|}{$\mid \begin{array}{l}\text { アラント } \\
\text { イン窒素 }\end{array}$} & \multirow{2}{*}{$\begin{array}{c}\text { 尿糖 } \\
\mathrm{g}\end{array}$} \\
\hline & & & & & & $g$ & Pr.kg & $\mathrm{mg}$ & $\%$ & $\mathrm{mg}$. & $\%$ & $\mathrm{mg}$. & $\%$ & \\
\hline & $\mathrm{X} \llbracket 4$ & 8.50 & 305 & 1015 & 4.279 & 3.031 & & 2.1 & & 6.9 & & 101 & & \\
\hline & 5 & 8.45 & 240 & 1018 & 4.279 & 3.014 & & 3.3 & & 5.2 & & 85 & & \\
\hline & 6 & 8.60 & 215 & 1020 & 4.279 & 3.185 & & 2.8 & & 4.5 & & 106 & & \\
\hline & 7 & 8.60 & 325 & 1015 & 4.279 & 3.108 & & 3.5 & & $\underline{5.5}$ & & 104 & & \\
\hline & 平均 & 8.54 & 294 & 1017 & 4.279 & 3.085 & 0.361 & 2.9 & 0.09 & 5.5 & 0.18 & 99 & 3.21 & \\
\hline \multirow{8}{*}{ 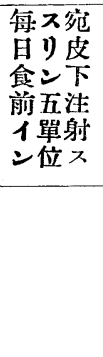 } & 8 & 8.40 & 235 & 1017 & 4.279 & 2.905 & & 4.0 & & 5.0 & & 77 & & \\
\hline & 9 & 8.50 & 170 & 1025 & 4.279 & 2.884 & & 2.5 & & 6.9 & & 92 & & \\
\hline & 10 & 8.50 & 260 & 1020 & 4.279 & 3.283 & & 2.8 & & 5.1 & & 95 & & \\
\hline & 平均 & 8.47 & 222 & 1021 & 4.279 & 3.024 & 0.356 & 3.1 & 0.10 & 5.7 & 0.19 & 88 & 2.91 & \\
\hline & 11 & 8.55 & 190 & 1021 & 4.279 & 2.989 & & 2.8 & & 5.9 & & 91 & & \\
\hline & 12 & 8.55 & 325 & 1017 & 4.279 & 3.154 & & 2.6 & & 6.4 & & 150 & & \\
\hline & 13 & 8.60 & 165 & 1025 & 4.279 & 3.052 & & 2.5 & & 6.5 & & 62 & & \\
\hline & 平均 & 8.57 & 227 & 1021 & 4.279 & 3.065 & 0.357 & 2.6 & 0.09 & 6.7 & 0.22 & 101 & 3.30 & \\
\hline \multirow{8}{*}{ 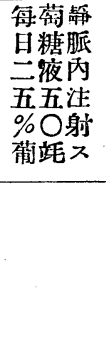 } & 14 & 8.55 & 380 & 1015 & 4.279 & 3.248 & & 2.8 & & 6.6 & & 118 & & 1.93 \\
\hline & 15 & 8.60 & 255 & 1019 & 4.279 & 2.944 & & 3.1 & & & & 129 & & 1.93 \\
\hline & 16 & 8.60 & 230 & 1021 & 4.279 & 2.896 & & 4.0 & & 7.1 & & 147 & & 1.93 \\
\hline & 平坛 & 8.58 & 288 & 1018 & 4.279 & 3.029 & 0.353 & 3.3 & 0.11 & 6.9 & 0.23 & 131 & 4.32 & 1.93 \\
\hline & 17 & 8.55 & 335 & 1015 & 4.279 & 3.038 & & 3.2 & & 6.6 & & 83 & & \\
\hline & 18 & 8.50 & 175 & 1026 & 4.279 & 3.199 & & 3.2 & & 7.8 & & 90 & & \\
\hline & 19 & 8.50 & 220 & 1020 & 4.279 & 3.192 & & 2.8 & & 8.0 & & 104 & & \\
\hline & 本均 & 852 & 243 & 1020 & 4.279 & 3.143 & 0.369 & 3.1 & 0.10 & 7.7 & 0.25 & 92 & 2.93 & \\
\hline \multirow{8}{*}{ 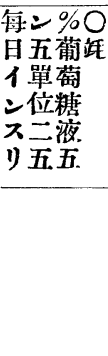 } & 20 & 8.50 & 285 & 1015 & 4.279 & 2.814 & & 3.5 & & 6.9 & . & 122 & & 1.38 \\
\hline & 21 & 8.55 & 215 & 1022 & 4.279 & 3.157 & & 3.3 & & 6.2 & & 126 & & 1.32 \\
\hline & 22 & 8.50 & 405 & 1014 & 4.279 & 3.045 & & 2.3 & & 7.9 & & 101 & & 1.62 \\
\hline & 本均 & 8.52 & 302 & 1017 & 4.279 & 3.002 & 0.353 & 3.0 & 0.10 & 7.0 & 0.23 & 116 & 3.84 & 1.44 \\
\hline & 23 & 8.55 & 245 & 1018 & 4.279 & 3.206 & & 2.1 & & 6.9 & & 76 & & \\
\hline & 24 & 8.55 & 250 & 1019 & 4.279 & 3.185 & & 3.5 & & 6.7 & & 126 & & \\
\hline & 25 & 8.55 & 235 & 1019 & 4.279 & 3.090 & & 2.8 & & 7.3 & & 106 & & \\
\hline & 平均 & 8.55 & 268 & 1019 & 4.279 & 3.160 & 0.370 & 2.8 & 0.09 & 7.0 & 0.22 & 103 & 3.26 & \\
\hline
\end{tabular}


綜二例 犬

\begin{tabular}{|c|c|c|c|c|c|c|c|c|c|c|c|c|c|c|}
\hline \multirow[t]{2}{*}{ II } & \multirow{2}{*}{ 日日 } & \multirow{2}{*}{$\begin{array}{l}\text { 體重 } \\
\mathrm{kg}\end{array}$} & \multirow{2}{*}{$\begin{array}{l}\text { 尿量 } \\
\text { c.c }\end{array}$} & \multirow{2}{*}{$\begin{array}{l}1 \text { 比重 }^{\circ} \mathrm{C} \\
15^{\circ}\end{array}$} & \multirow{2}{*}{$\begin{array}{c}\text { 㨞取 } \\
\text { 窒素 } \\
\mathrm{g}\end{array}$} & \multicolumn{2}{|c|}{ 尿總窒素 } & \multicolumn{2}{|c|}{\begin{tabular}{|l} 
ブリン想 \\
基窒素
\end{tabular}} & \multicolumn{2}{|c|}{ |尿酸筀素 } & \multicolumn{2}{|c|}{$\begin{array}{l}\text { アラント } \\
\text { イン臸素 }\end{array}$} & \multirow{2}{*}{$\begin{array}{c}\text { 尿糖 } \\
\mathrm{g}\end{array}$} \\
\hline & & & & & & $\mathrm{g}$ & Pr.kg & $\mathrm{mg}$ & $\%$ & $\mathrm{mg}$ & $\%$ & $\mathrm{mg}$ & $\%$ & \\
\hline & 121 & 8.35 & 280 & 1014 & 2.615 & 2.530 & & 3.1 & & 4.5 & & 98.0 & & \\
\hline & 22 & 8.35 & 180 & 1018 & 2.615 & 2.555 & & 2.4 & & 3.4 & & 72.8 & & \\
\hline & 23 & 8.35 & 5170 & 1019 & 2.615 & 2.338 & & 2.4 & & 4.3 & & 77.0 & & \\
\hline & 本均 & 8.35 & 210 & 1017 & 2.615 & 2.441 & 0.292 & 2.6 & 0.11 & 4.1 & 0.17 & 82.6 & 3.38 & \\
\hline \multirow{10}{*}{$\begin{array}{l}\text { 每單 } \\
\text { 日位 } \\
\text { 1宛 } \\
\text { 亡皮 } \\
\text { ス下 } \\
\text { リ注 } \\
\text { 之射 } \\
\text { 五 } \\
\end{array}$} & 24 & 8.35 & 190 & 1013 & 2.615 & 2.478 & & 2.1 & & 4.3 & & 61.6 & & \\
\hline & 25 & 8.35 & 160 & 1018 & 2.615 & 2.500 & & 1.7 & & 3.9 & & 64.4 & & \\
\hline & 26 & 8.35 & 200 & 1013 & 2.615 & 2.184 & & 2.6 & & 3.8 & & 56.0 & & \\
\hline & 27 & 8.30 & 125 & 1028 & 2.615 & 2.495 & & 3.8 & & 4.3 & & 51.8 & & \\
\hline & 平均 & 8.34 & 169 & 1018 & 2.615 & 2.389 & 0.286 & 2.6 & 0.11 & 3.8 & 0.16 & 58.2 & 2.44 & \\
\hline & 28 & 8.20 & 225 & 1014 & 2.615 & 2.467 & & 3.6 & & 4.1 & & & & \\
\hline & 29 & 8.20 & 210 & 1016 & 2.615 & 2.581 & & 1.7 & & 4.1 & & & & \\
\hline & 30 & 8.20 & 225 & 1014: & 2.615 & 2.562 & & & & 3.8 & & 47.6 & & \\
\hline & 31 & 8.20 & 180 & 1017 & 2.615 & 2.569 & & 2.4 & & 3.9 & & 42.0 & & \\
\hline & 平均 & 8.20 & 210 & 1015 & 2.615 & 2.545 & 0.310 & 2.6 & 0.10 & 4.0 & 0.16 & 44.8 & 1.76 & \\
\hline \multirow{8}{*}{$\begin{array}{l}\text { 三液日 } \\
\text { 吾静 } \\
\text { \%O脈 } \\
\text { 葡竓内 } \\
\text { 萄注 } \\
\text { 糖每射 }\end{array}$} & 【1 1 & 8.15 & 190 & 1016 & 2.615 & 2.401 & & 2.7 & & 3.8 & & 72.8 & & 1.39 \\
\hline & 2 & 8.15 & 280 & 1012 & 2.615 & 2.331 & & 2.5 & & 3.9 & & 39.2 & & 1.79 \\
\hline & 3 & 8.10 & 255 & 1013 & 2.615 & 2.275 & & 2.5 & & 3.8 & & $\theta 1.6$ & & 2.08 \\
\hline & 平均 & 8.13 & 241 & 1014 & 2.615 & 2.336 & 0.287 & 2.7 & 0.11 & 3.8 & 0.16 & 57.9 & 2.48 & 1.75 \\
\hline & 4 & 8.05 & 280 & 1009 & 2615 & 2.310 & & 1.7 & & 3.9 & & 22.4 & & \\
\hline & 5 & 8.05 & 230 & 1012 & 2.615 & 2.408 & & 2.1 & & 3.9 & & 22.4 & & \\
\hline & 6 & 8.10 & 185 & 1017 & 2.615 & 2.485 & & 2.1 & & 3.8 & & 30.8 & & \\
\hline & 本均 & 8.07 & 232 & 1013 & 2.615 & 2.401 & 0.298 & 2.0 & 0.09 & 3.9 & 0.16 & 28.5 & 1.19 & \\
\hline \multirow{9}{*}{ 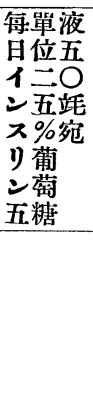 } & 7 & 8.10 & 250 & 1011 & 2.615 & 2.478 & & 2.1 & & 3.2 & & 42.0 & & 0.56 \\
\hline & 8 & 8.10 & 220 & 1013 & 2.615 & 2.233 & & 1.9 & & 3.6 & & 21.0 & & 1.70 \\
\hline & 9 & 8.25 & 200 & 1014 & 2.615 & 2.354 & & 2.1 & & 3.9 & & 63.0 & & 1.78 \\
\hline & 10 & 8.15 & 290 & 1011 & 2.615 & 2.023 & & 1.7 & & 4.1 & & 35.0 & & 1.04 \\
\hline & 平均 & 8.15 & 240 & 1012 & 2.615 & 2.272 & 0.279 & 2.0 & $0.0 y$ & 3.7 & 0.16 & 40.2 & 1.77 & 1.41 \\
\hline & 13 & 8.15 & 270 & 1010 & 2.615 & 2.495 & & 1.7 & & 3.1 & & 26.8 & & \\
\hline & 14 & 8.10 & 190 & 1015 & 2.615 & 2.317 & & 2.1 & & 3.4 & & 53.0 & & \\
\hline & 15 & 8.05 & 215 & 1014 & 2.615 & 2.520 & & 1.9 & & 3.9 & & 42.0 & & \\
\hline & 平均 & 8.10 & 225 & 1013 & 2.615 & 2.444 & 0.317 & 1.9 & 0.08 & 3.5 & 0.14 & 40.6 & 1.66 & \\
\hline
\end{tabular}


第 三 例 犬

\begin{tabular}{|c|c|c|c|c|c|c|c|c|c|c|c|c|}
\hline \multirow{2}{*}{ III } & \multirow{2}{*}{ 月日 } & \multicolumn{2}{|c|}{ 體重|尿量 } & \multirow{2}{*}{$\left|\begin{array}{l}\text { 比重 } \\
15^{\circ} \mathrm{C}\end{array}\right|$} & \multirow{2}{*}{$\begin{array}{c}\text { 㰆取 } \\
\text { 至素 } \\
\mathrm{g}\end{array}$} & \multicolumn{2}{|c|}{ 尿總窒甞 } & \multicolumn{2}{|c|}{ 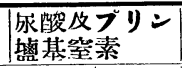 } & \multicolumn{2}{|c|}{ 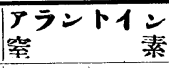 } & \multirow{2}{*}{$\begin{array}{c}\text { 尿 糖 } \\
\mathrm{g}\end{array}$} \\
\hline & & $\mathrm{kg}$ & c.c & & & $\mathrm{g}$ & Pr.kg & $\mathrm{mg}$ & $\%$ & $\mathrm{mg}$ & $\%$ & \\
\hline & $\| 123$ & $|8.00|$ & $|140|$ & $|1021|$ & 2.644 & $2.016^{\circ}$ & & 20.1 & & 42.0 & & \\
\hline & 24 & 8.05 & 175 & 1015 & 2644 & 2.093 & & 21.4 & & 53.2 & & \\
\hline & 25 & 8.05 & 230 & 1012 & 2.644 & 2.142 & & 17.7 & & 51.6 & & \\
\hline & 26 & 8.05 & 200 & 1013 & 2.644 & 2.282 & & 18.0 & & 56.0 & & \\
\hline & $\mathbb{m} 1$ & 8.10 & 160 & 1015 & 2.644 & 2.058 & & 20.8 & & 30.8 & & \\
\hline & 平均 & 8.05 & 181 & 1015 & 2.644 & 2.118 & 0.263 & 19.6 & 0.93 & 46.7 & 2.20 & \\
\hline \multirow{9}{*}{$\begin{array}{l}\text { 每之注 } \\
\text { 日五射 } \\
\text { 1單 } \\
\text { 位 } \\
\text { 度 } \\
\text { り年 }\end{array}$} & 2 & 8.10 & 125 & 1020 & 2.644 & 1.883 & & 22.9 & & 32.2 & & \\
\hline & 3 & 8.05 & 235 & 1011 & 2.644 & 1.848 & & 20.1 & & 39.2 & & \\
\hline & 4 & 8.05 & 230 & 1010 & 2.644 & 1.775 & & 17.9 & & 33.6 & & \\
\hline & 平均 & 8.07 & 197 & 1013 & 2.644 & 1.835 & 0.227 & 20.3 & 1.11 & 35.0 & 1.91 & \\
\hline & $\tilde{\delta}$ & 8.05 & 170 & 1014 & 2.644 & 1.652 & & 18.4 & & 50.4 & & \\
\hline & 6 & 8.05 & 195 & 1011 & 2.644 & 1.421 & & 17.9 & & 42.0 & & \\
\hline & 7 & 8.05 & 170 & 1014 & 2.644 & 1.638 & & 20.0 & & 30.8 & & \\
\hline & 9 & 8.05 & 190 & 1013 & 2.644 & 1.519 & & 17.5 & & 44.8 & & \\
\hline & 平均 & 8.05 & 181 & 1013 & 2.644 & 1.558 & 0.194 & 18.4 & 1.11 & 42.0 & 2.63 & \\
\hline \multirow{8}{*}{ 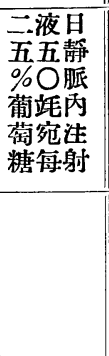 } & 10 & 8.10 & 170 & 1013 & 2.644 & 1.239 & & 18.9 & & 44.8 & & \\
\hline & 11 & 8.15 & 220 & 1008 & 2.644 & 1.316 & & 17.0 & & 49.0 & & \\
\hline & 12 & 8.10 & 180 & 1015 & 2.644 & 1.337 & & 18.4 & & 63.0 & & \\
\hline & 平均 & 8.12 & 130 & 1012 & 2.644 & 1.297 & 0.160 & 18.1 & 1.39 & 53.3 & 4.03 & \\
\hline & 13 & $8.15 \mid$ & 195 & 1012 & 2.644 & 1.330 & & 17.2 & & 39.2 & & \\
\hline & 14 & 8.20 & 140 & 1020 & 2.644 & 1.508 & & 14.5 & & 50.4 & & \\
\hline & 15 & 8.15 & 190 & 1015 & 2.644 & 1.407 & & 14.0 & & 56.0 & & \\
\hline & 平均 & 8.17 & 175 & 1016 & 2.644 & 1.415 & 0.166 & 15.0 & 1.08 & 48.5 & 3.43 & \\
\hline \multirow{8}{*}{ 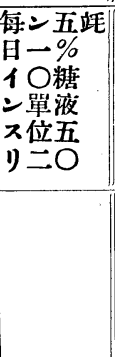 } & 16 & $|8.15|$ & 130 & $|1023|$ & 2.644 & 1.253 & & 12.7 & & $74: 2$ & & 1.79 \\
\hline & 17 & 8.15 & 220 & 1012 & 2.644 & 1.344 & & 13.3 & & 70.0 & & 1.39 \\
\hline & 18 & 8.15 & 230 & 1013 & 2.644 & 1.396 & & 8.8 & & 57.4 & & 1.56 \\
\hline & 本均 & 8.15 & 193 & 1016 & 2.644 & 1.331 & 0.163 & 11.6 & 0.87 & 67.2 & 5.05 & 1.58 \\
\hline & 19 & 8.15 & 180 & 1013 & 2.644 & 1.477 & & 15.2 & & 54.6 & & \\
\hline & 20 & -8.20 & 135 & 1020 & 2.644 & 1.491 & & 16.3 & & 61.6 & & \\
\hline & 21 & 8.20 & 195 & 1015 & 2.644 & 1.502 & & 13.0 & & 44.8 & & \\
\hline & 平均 & 8.18 & 170 & 1016 & 2.644 & 1.490 & 0.170 & 14.8 & 0.99 & 53.7 & 3.60 & \\
\hline
\end{tabular}


第 四 例 犬

\begin{tabular}{|c|c|c|c|c|c|c|c|c|c|c|c|c|}
\hline \multirow{2}{*}{11} & \multirow{2}{*}{ 月日 } & \multirow{2}{*}{$\begin{array}{c}\text { 體重 } \\
\mathrm{kg}\end{array}$} & \multirow{2}{*}{$\begin{array}{l}\text { 尿量 } \\
\text { c.c }\end{array}$} & \multirow{2}{*}{$\begin{array}{l}\text { 比重 } \\
15^{\circ} \mathrm{C}\end{array}$} & \multirow{2}{*}{\begin{tabular}{|c|} 
攝取 \\
跮素 \\
$\mathrm{g}$
\end{tabular}} & \multicolumn{2}{|c|}{ 尿總䓨素 } & \multicolumn{2}{|c|}{ 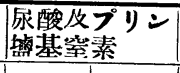 } & \multicolumn{2}{|c|}{\begin{tabular}{|l|} 
アラシトイン \\
竍素
\end{tabular}} & \multirow{2}{*}{$\begin{array}{c}\text { 尿 糖 } \\
\mathrm{g}\end{array}$} \\
\hline & & & & & & $\mathrm{g}$ & $\mid$ Pr.kg $\mid$ & $\mathrm{mg}$ & $\%$ & $\mathrm{mg}$ & $\%$ & \\
\hline & $\mid \begin{array}{c}\text { 田20 } \\
21 \\
22 \\
\text { 平均 }\end{array}$ & $\mid \begin{array}{l}8.20 \\
8.20 \\
8.20 \\
8.20\end{array}$ & $\begin{array}{l}135 \\
195 \\
185 \\
172\end{array}$ & $\begin{array}{l}1020 \\
1015 \\
1015 \\
1017\end{array}$ & \begin{tabular}{l|}
2.013 \\
2.013 \\
2.013 \\
2.013
\end{tabular} & $\begin{array}{l}1.491 \\
1.502 \\
1.550 \\
1.514\end{array}$ & 0.185 & $\begin{array}{l}16.28 \\
12.95 \\
16.10 \\
15.11\end{array}$ & 0.10 & $\begin{array}{l}61.6 \\
44.8 \\
56.1 \\
54.1\end{array}$ & 3.57 & \\
\hline \multirow[t]{2}{*}{ 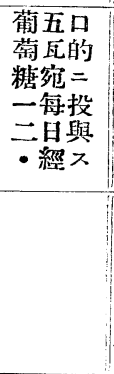 } & $\mid \begin{array}{c}23 \\
24 \\
25 \\
\text { 平均 }\end{array}$ & $\left|\begin{array}{l}8.25 \\
8.25 \\
8.35 \\
8.28\end{array}\right|$ & $\begin{array}{r}75 \\
130 \\
155 \\
120\end{array}$ & $\left|\begin{array}{l}1018 \\
1016 \\
1017\end{array}\right|$ & $\begin{array}{l}2.013 \\
2.013 \\
2.013 \\
2.013\end{array}$ & $\begin{array}{l}1.436 \\
1.390 \\
1.547 \\
1.472\end{array}$ & 0.177 & $\begin{array}{l}17.50 \\
10.85 \\
12.60 \\
13.65\end{array}$ & 0.93 & $\begin{array}{l}53.2 \\
42.0 \\
61.6 \\
52.3\end{array}$ & 3.55 & 0.33 \\
\hline & \begin{tabular}{c|}
26 \\
27 \\
28 \\
斥均
\end{tabular} & $\begin{array}{l}8.35 \\
8.35 \\
8.35 \\
8.35\end{array}$ & \begin{tabular}{l|l}
170 & \\
170 & 1 \\
160 & 1 \\
167 & 1
\end{tabular} & $\left|\begin{array}{l}1016 \\
1016 \\
1018 \\
1017\end{array}\right|$ & $\begin{array}{l}2.013 \\
2.013 \\
2.013 \\
2.013\end{array}$ & $\begin{array}{l}1.582 \\
1.550 \\
1.568 \\
1.567\end{array}$ & 0.186 & $\begin{array}{l}13.30 \\
12.60\end{array}$ & 0.83 & $\begin{array}{l}56.0 \\
61.6 \\
56.0 \\
57.7\end{array}$ & 3.62 & \\
\hline \multirow[t]{2}{*}{ 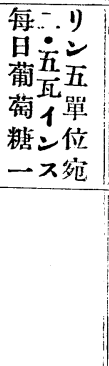 } & $\begin{array}{c}29 \\
30 \\
31 \\
\text { 平均 }\end{array}$ & $\left|\begin{array}{l}8.40 \\
8.45 \\
8.45 \\
8.43\end{array}\right|$ & $\begin{array}{l}100 \\
185 \\
155 \\
147\end{array}$ & $\left|\begin{array}{l}1026 \\
1017 \\
1021 \\
1021\end{array}\right|$ & $\begin{array}{l}2.013 \\
2.013 \\
2.013 \\
2.013\end{array}$ & $\begin{array}{l}1.456 \\
1631 \\
1.589 \\
1.559\end{array}$ & 0.185 & $\begin{array}{r}9.80 \\
10.85 \\
9.28 \\
9.98\end{array}$ & 0.64 & $\begin{array}{l}42.0 \\
50.4 \\
74.2 \\
55.5\end{array}$ & 3.56 & 0.26 \\
\hline & $\mid \begin{array}{r}1 \\
2 \\
3 \\
4\end{array}$ & $\begin{array}{l}8.45 \\
8.50 \\
8.50 \\
8.48\end{array}$ & \begin{tabular}{l|}
150 \\
125 \\
190 \\
155
\end{tabular} & $\left|\begin{array}{l}1019 \\
1025 \\
1019 \\
1021\end{array}\right|$ & $\begin{array}{l}2.013 \\
2.013 \\
2.013 \\
2.013\end{array}$ & $\begin{array}{l}1.603 \\
1.533 \\
1.704 \\
1.613\end{array}$ & 0.190 & $\begin{array}{r}9.45 \\
11.20 \\
10.85 \\
10.50\end{array}$ & 0.65 & $\begin{array}{l}80.2 \\
66.4 \\
86.2 \\
77.6\end{array}$ & 4.81 & \\
\hline
\end{tabular}

\begin{tabular}{|c|c|c|c|c|c|c|c|c|c|c|c|}
\hline & & 第 & $\begin{array}{l}\text { - 例 } \\
\text { 食 飭 } \\
\end{array}$ & & & 第 食 & \begin{tabular}{|c|} 
\\
\end{tabular} & 第 三 & $\begin{array}{ll}\text { E } & \text { 例 } \\
& \text { 飭 } \\
\end{array}$ & \begin{tabular}{|ll} 
第 & \multicolumn{2}{|l}{} \\
犬 & 食
\end{tabular} & $\begin{array}{ll}\text { 西例 } \\
\text { 食 } \\
\text { 䬲 }\end{array}$ \\
\hline & & 量 & $\begin{array}{c}\begin{array}{c}\text { 䇪素量 } \\
\mathrm{g}\end{array} \\
\end{array}$ & & & 量 & $\left|\begin{array}{c}\text { 䇪素量 } \\
\mathrm{g}\end{array}\right|$ & 量 & $\begin{array}{c}\text { 䇪素量 } \\
\mathrm{g}\end{array}$ & \multicolumn{2}{|r|}{$\begin{array}{c}\text { 窒素量 } \\
\mathrm{g}\end{array}$} \\
\hline 白 & 米 & $150 \mathrm{~g}$ & 1.677 & 牛 & 搗，米 & $150 \mathrm{~g}$ & 1.893 & $150 \mathrm{~g}$ & - & $100 \mathrm{~g}$ & 1.262 \\
\hline 牛 赤 & 肉 & $75 \mathrm{~g}$ & 2.515 & ラク & トゲーン & $20 \mathrm{~s}$ & 0.722 & $20 \mathrm{~g}$ & 0.722 & $20 \mathrm{~g}$ & 0.722 \\
\hline 醔 & 油 & 15 c.c. & 0.087 & 醬 & 油 & - & - & 5c.c & 0.029 & 5 c.c & 0.029 \\
\hline 水 & & 略一定 & - & & 水 & 略一定 & - & 略一定 & - & 略一定 & \\
\hline 合 & 計 & & 4.279 & & 計 & & 2.615 & & 2.644 & & 2.013 \\
\hline
\end{tabular}




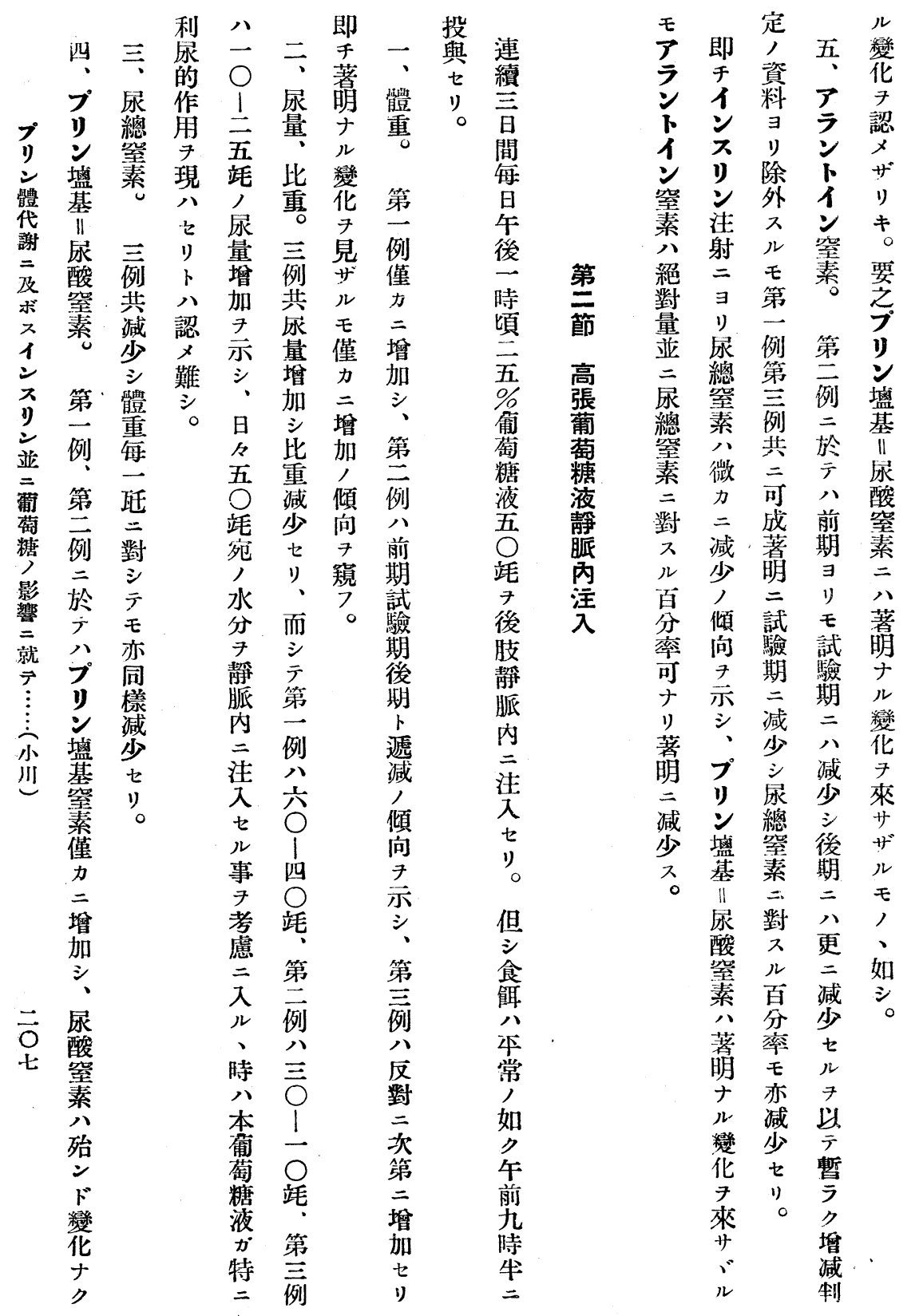




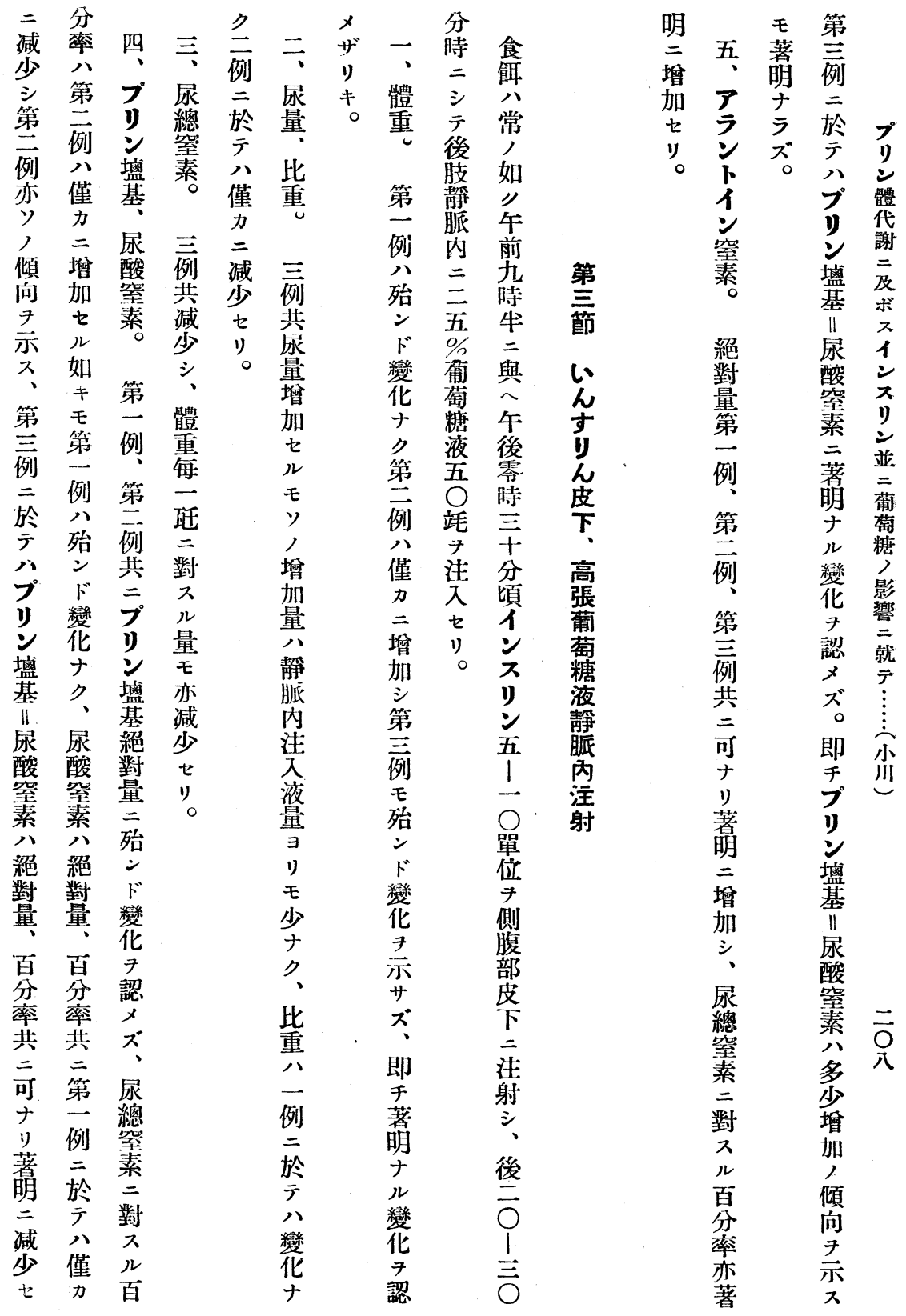



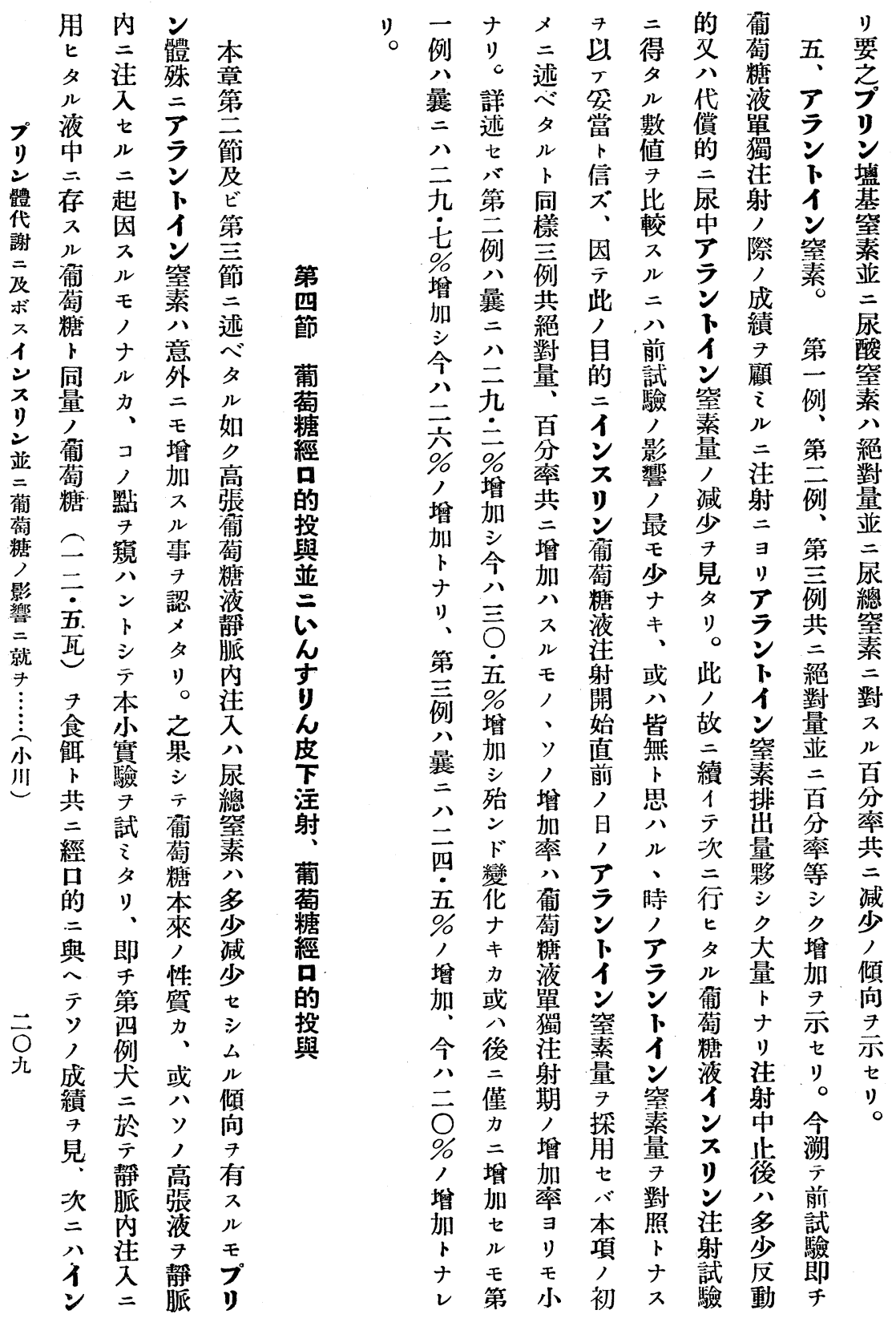


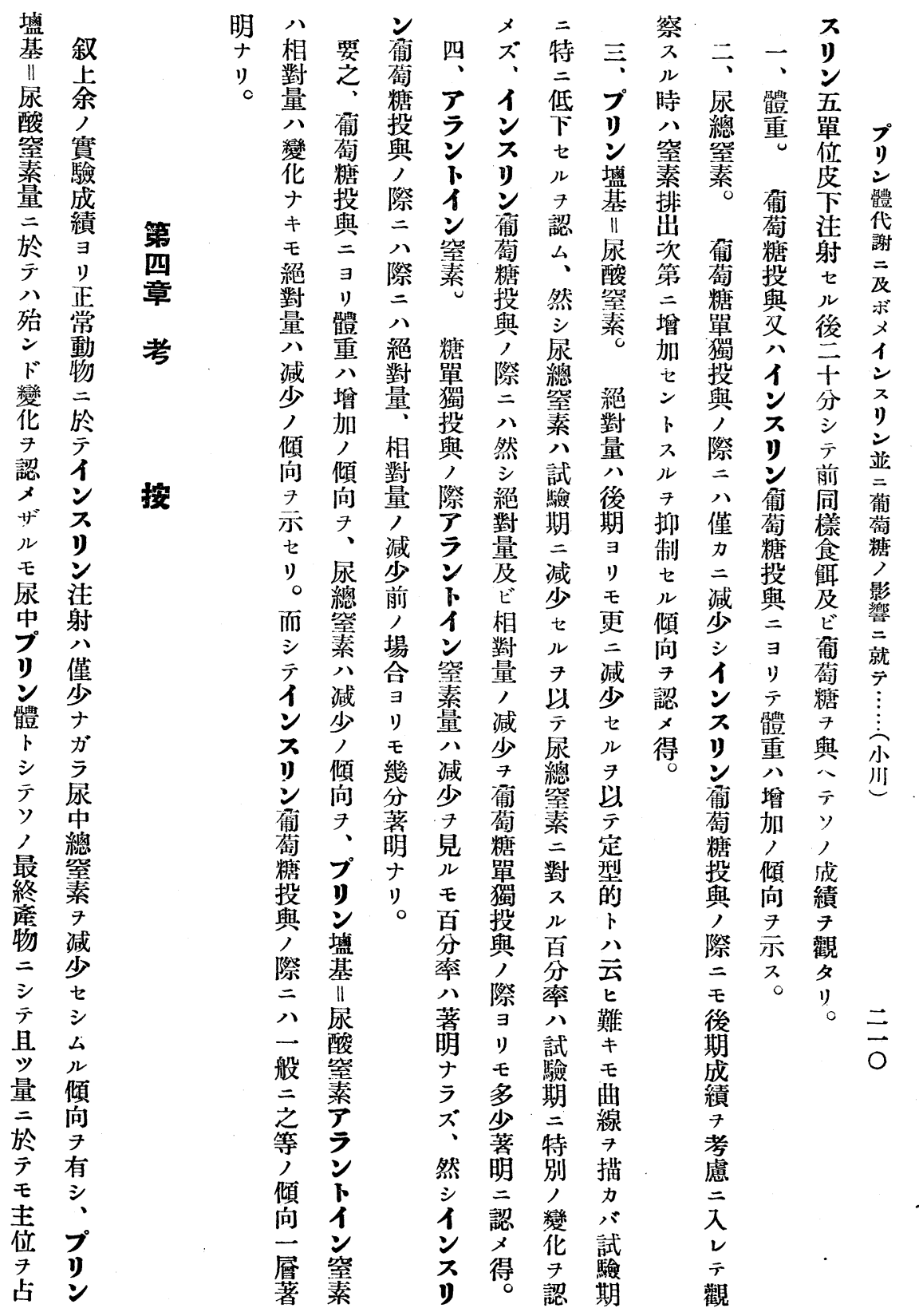




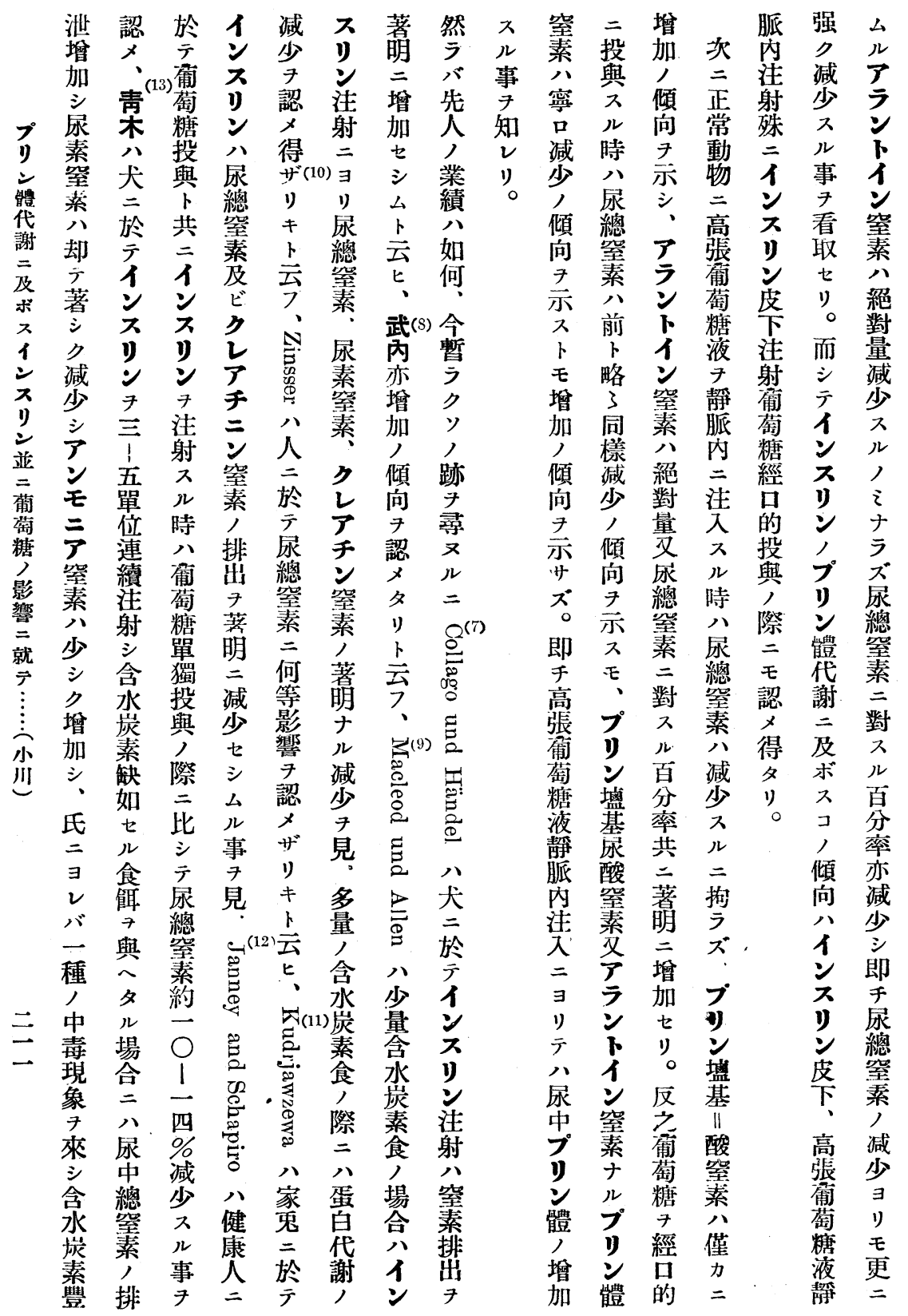




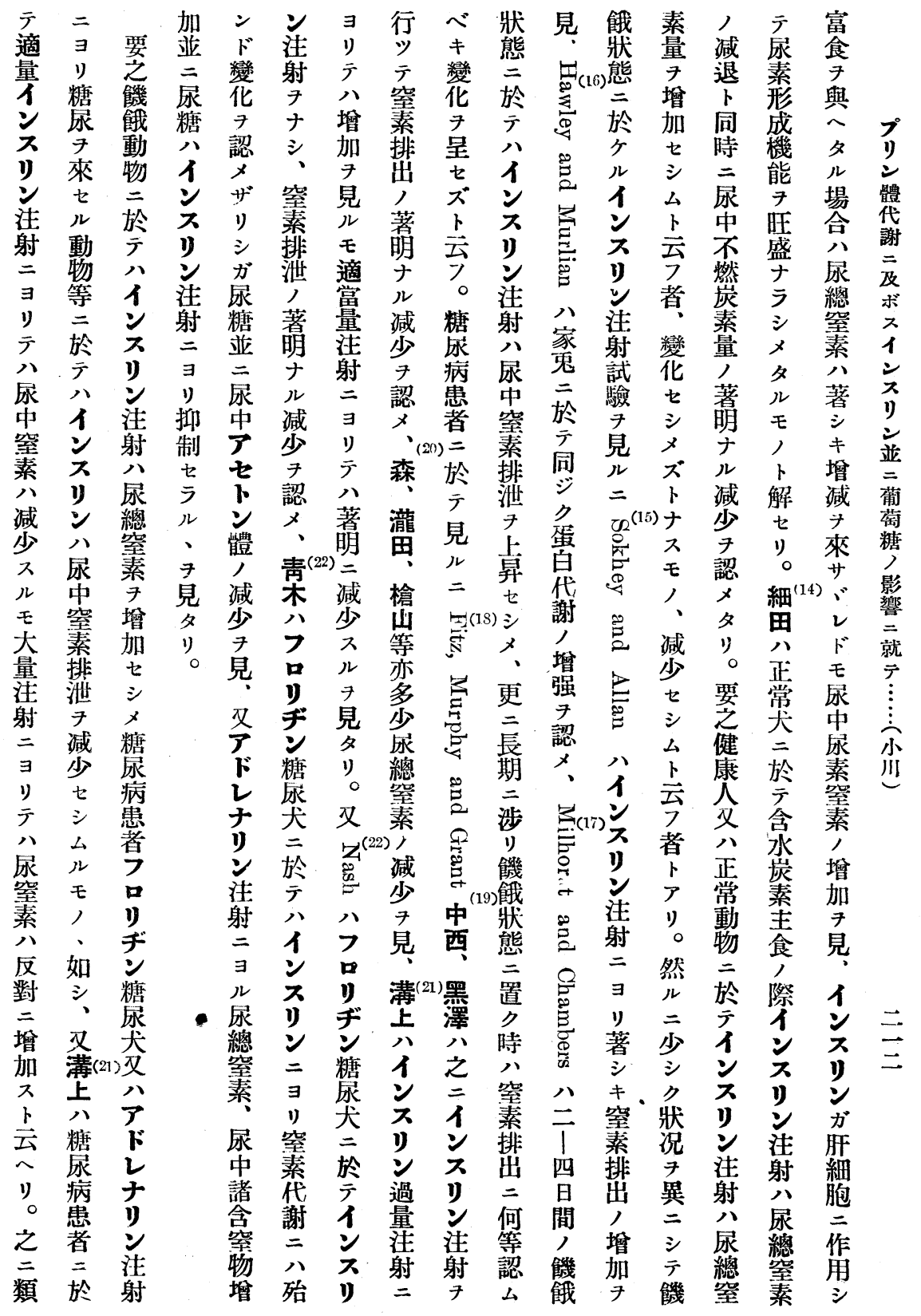




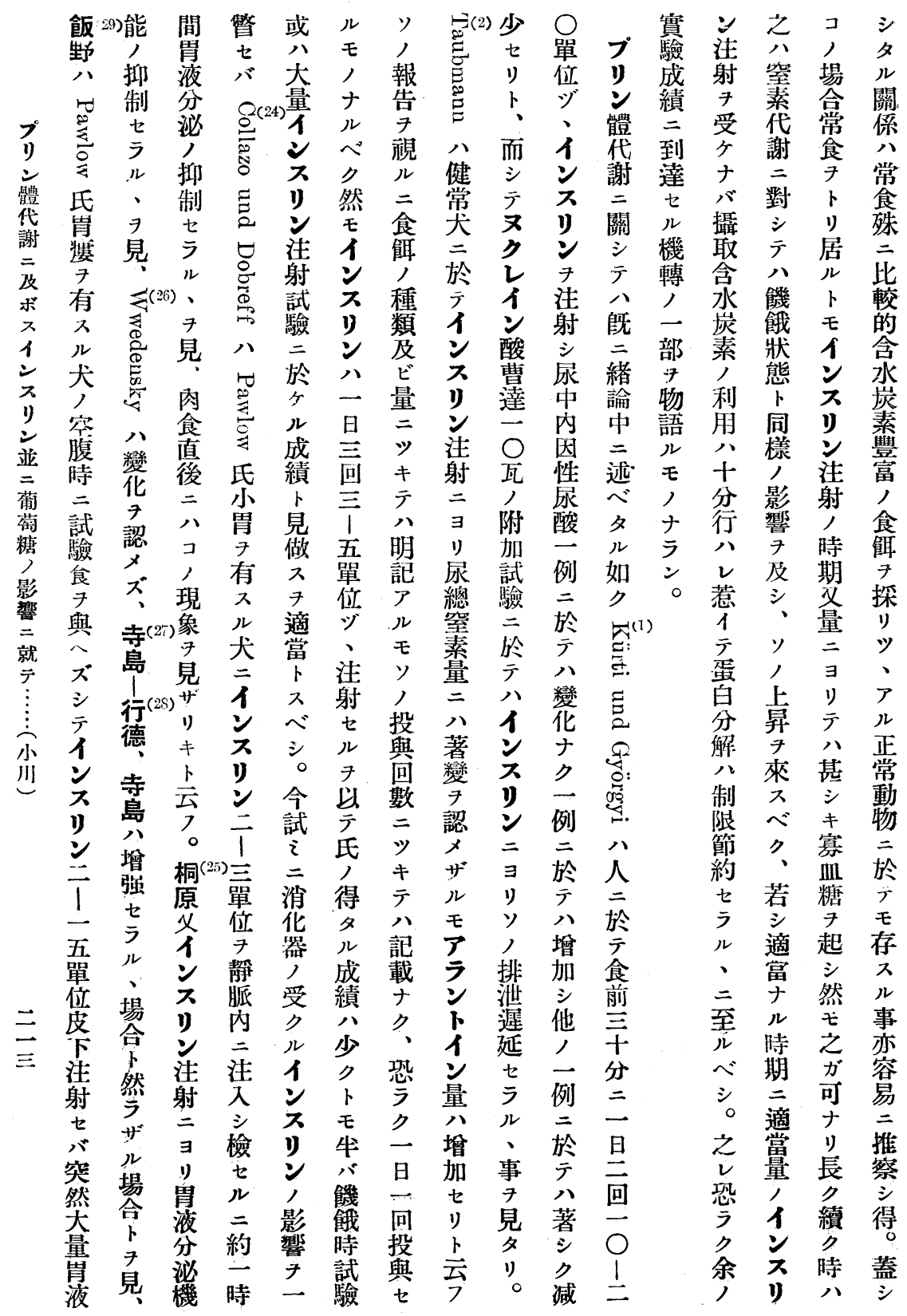




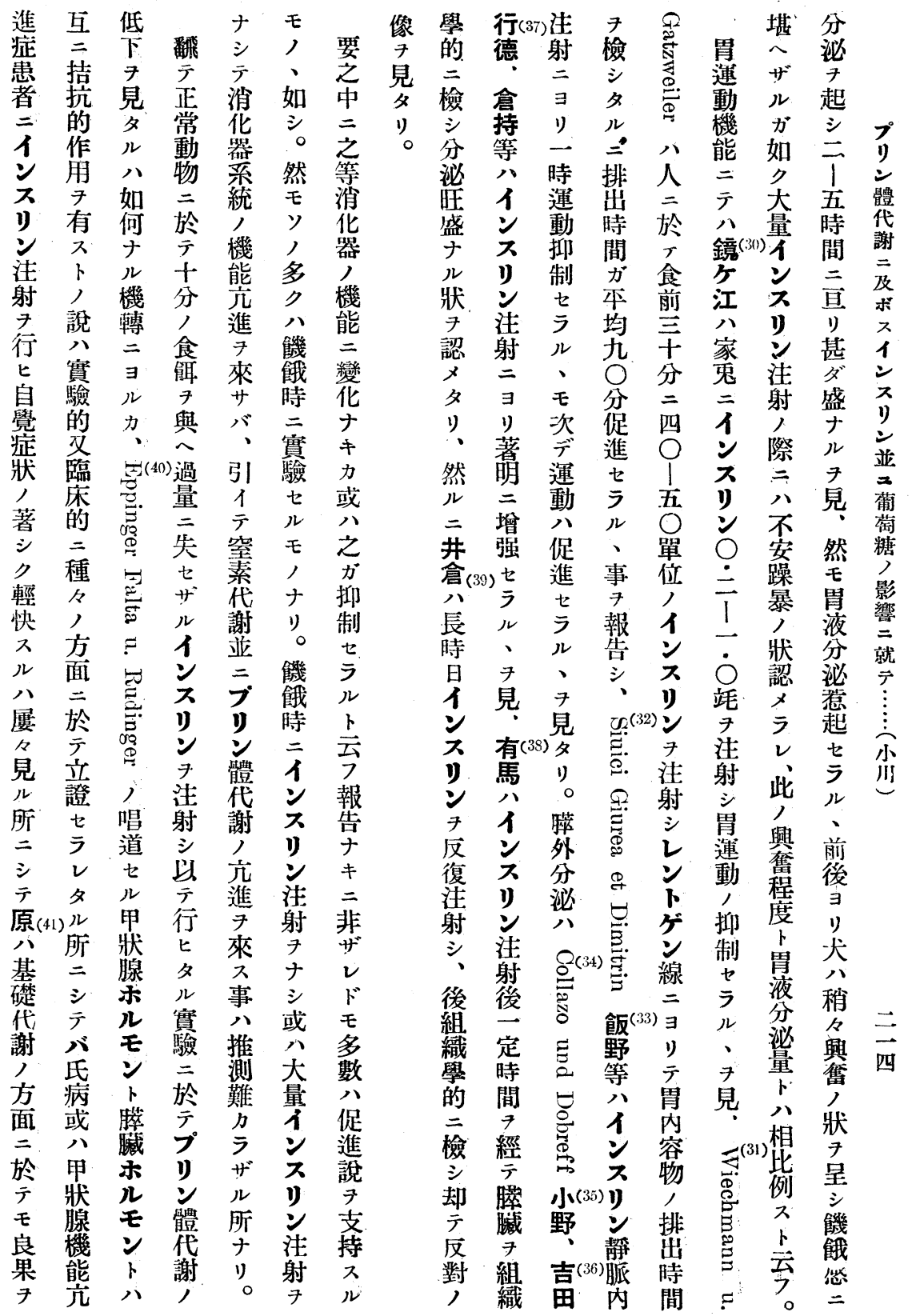




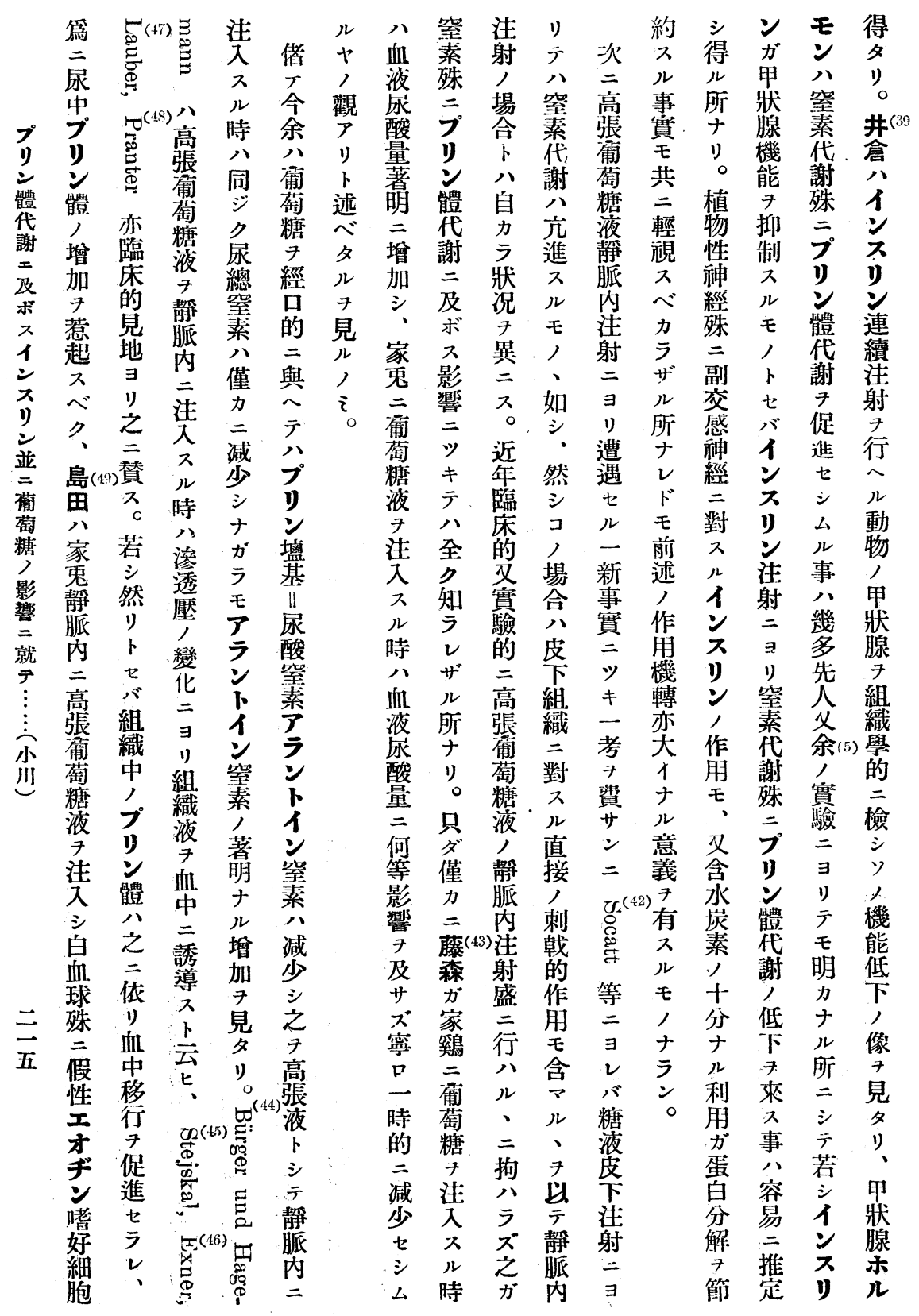




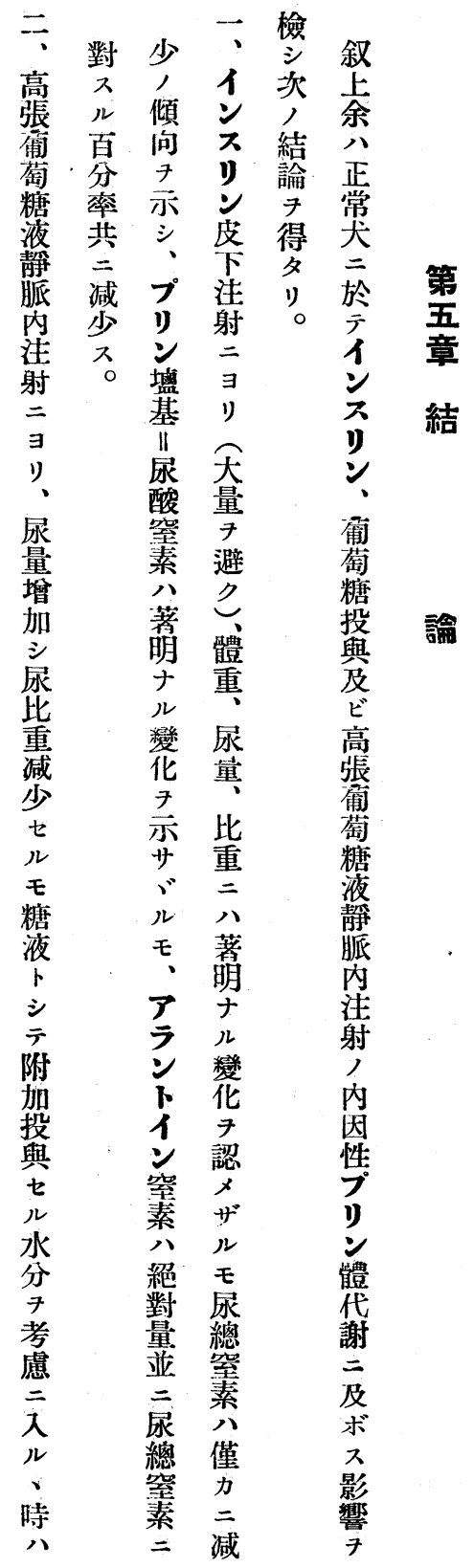

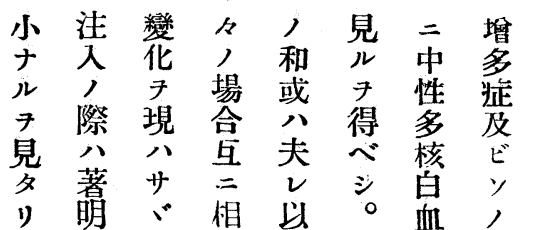
》。明 ‘相占。血, 次 第
吾
結

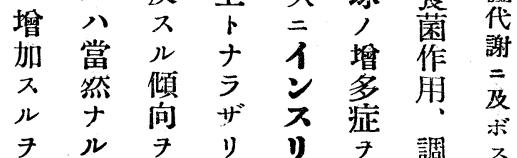

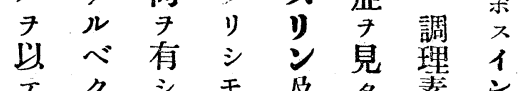
複り、卞各芯多素立

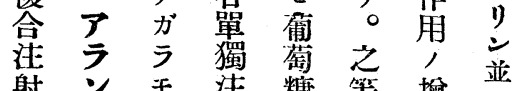
射 際1三人注氏 7 萄 增窒萻祭射業見糖 加素劣 然篎 减總余公就 然さ华少掌成暍

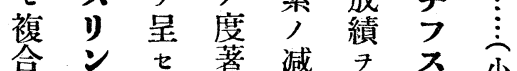

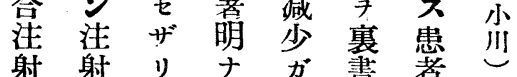
人

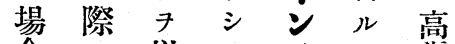

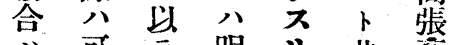

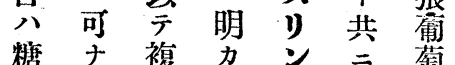
糖ナ複カ次三萄 單强注り公, 液 獨”射。葡機, 洼减際 プ 葡轉靜三

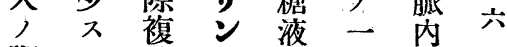
際 ル合熜單 部洼 增高射 基 薥 7 暗 加張, 尿射尔行 $\exists$ 糖 際酸, 射 り夜蓄窒際儿白 毛靜明素方堿, 血 度内儿, 個少卜殊 


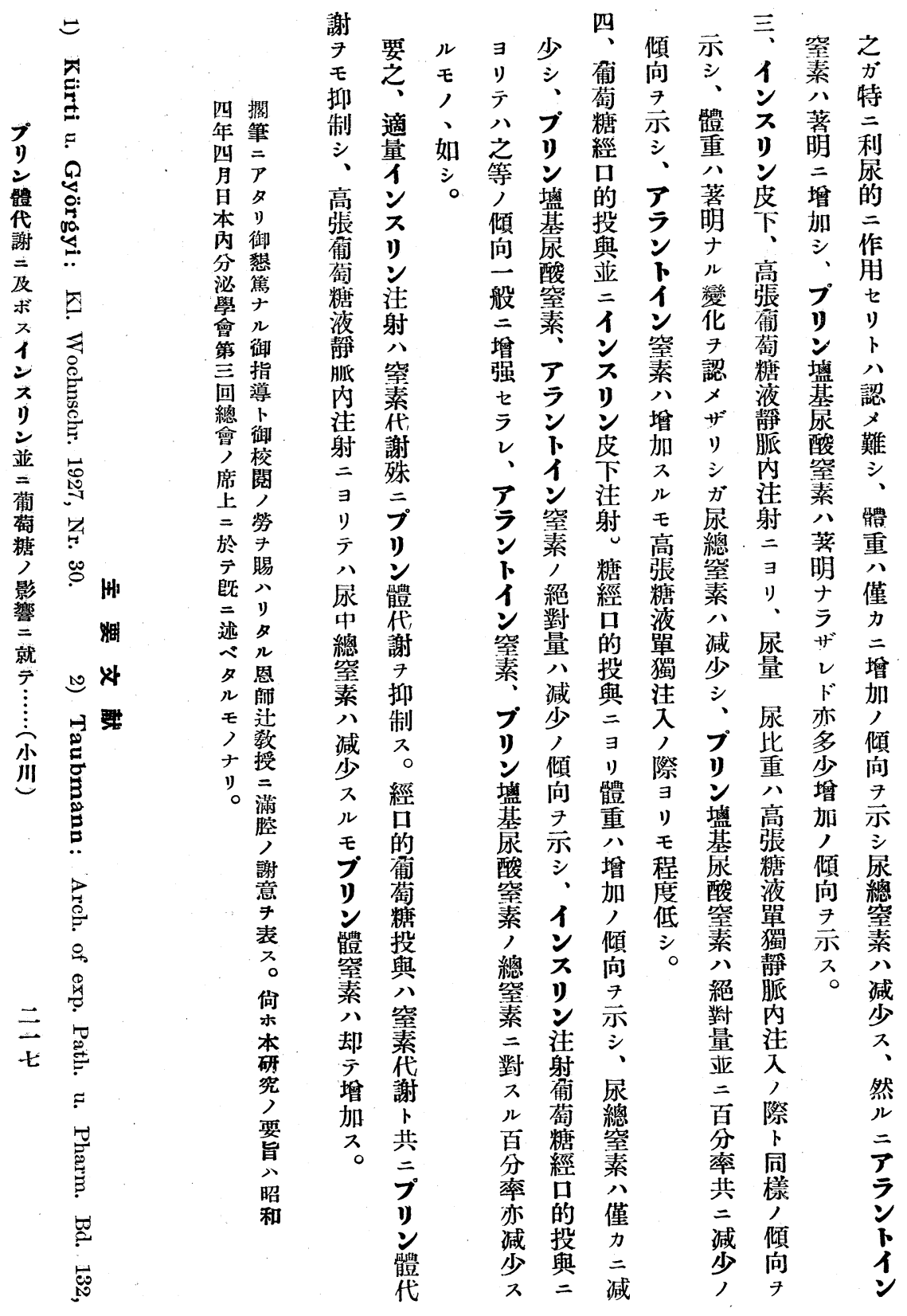




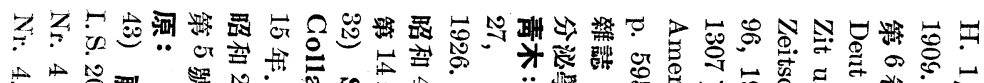
A

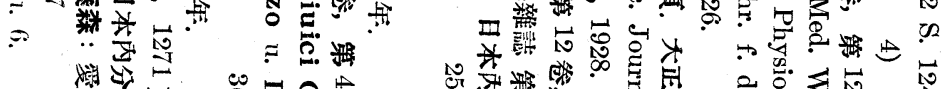

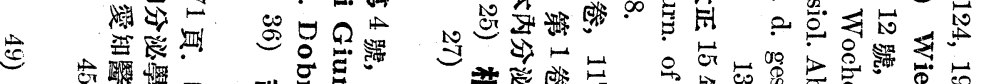

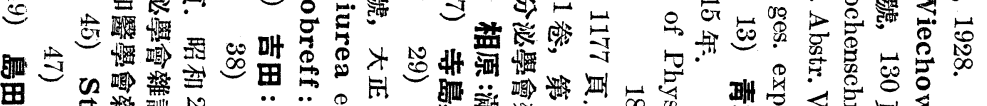

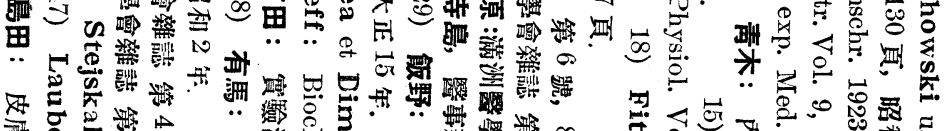

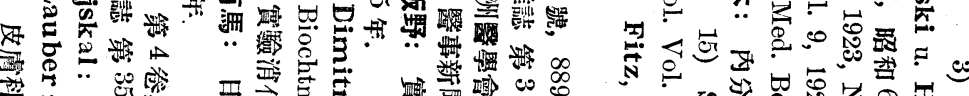

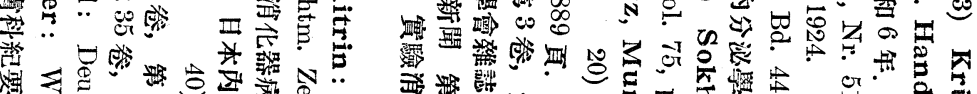

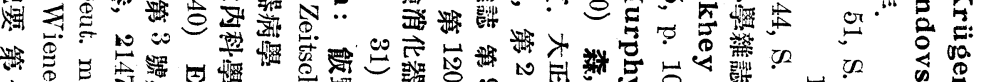

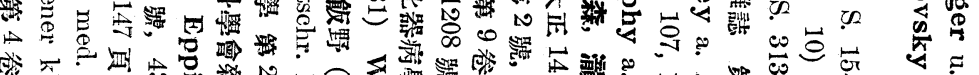

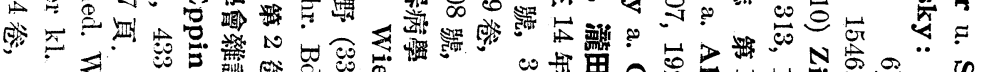

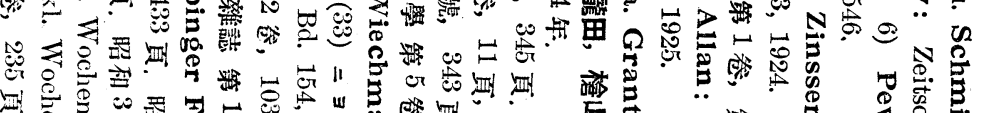

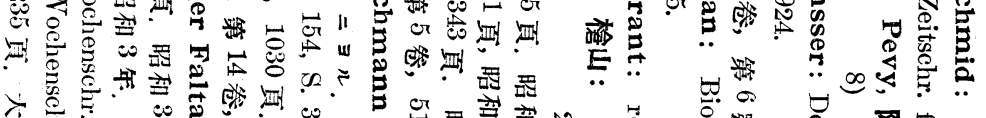

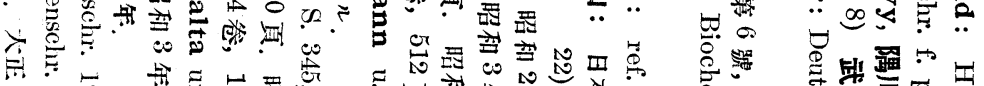

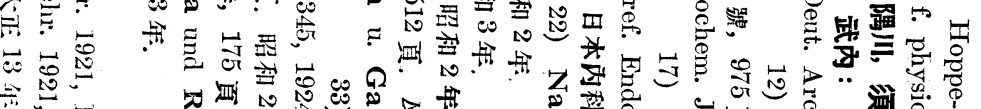

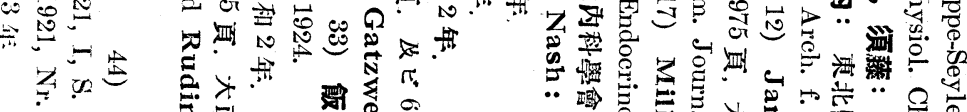

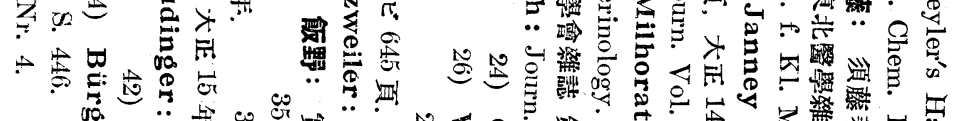
留

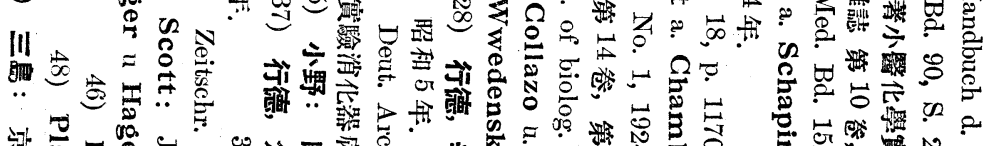

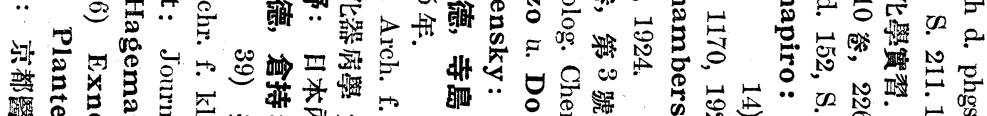

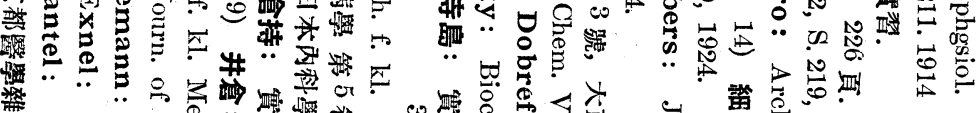

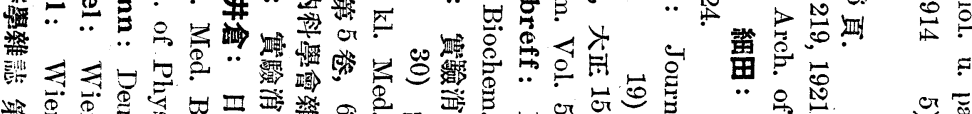

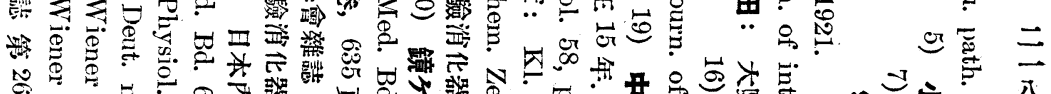

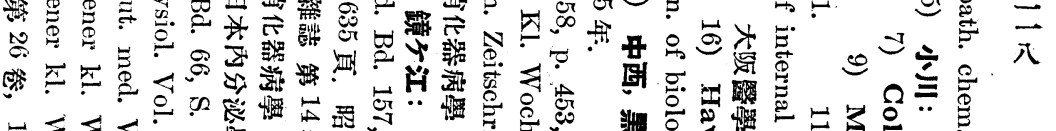

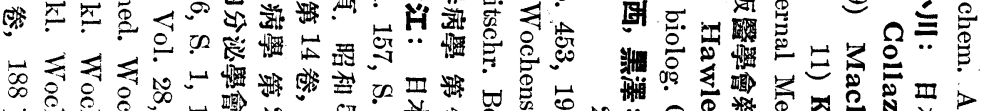

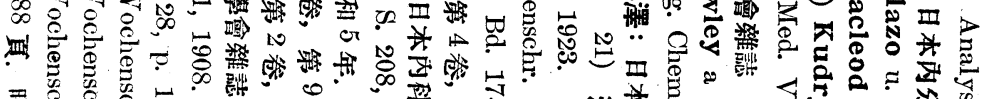

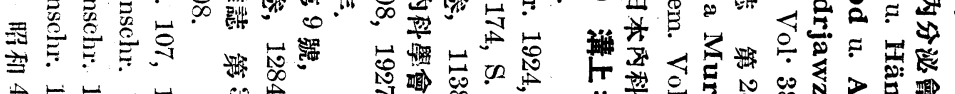

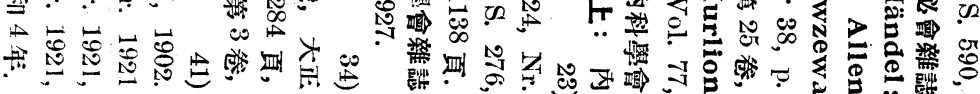


allmählich wieder auf seinen ursprünglichen Wert zurück.

(Autoreferat)

\title{
Ueber den Einfluss des Insulins und Traubenzuckers auf den Purinstoffwechsel.
}

\author{
Ton
}

Dr. T. Ogawa.

(Aus der I. med. Klinik der Kaiserl. Lniversität zu Kyoto in Japan.

Direktor: Prof. Dr. K. Tsuji.)

Ueber den Einfluss des Insulins auf den Stickstoffwechsel gibt es ziemlich viel Literatur, aber über den Purinstoffwechsel nur wenig. Leider herrscht unter den von vielen Autoren angegebenen Resultaten hinsichtlich des Stickstoff'wechsels keine Uebereinstimmung. Dasselbe ist auch bezüglich des Purinstoffwechsels der Fall. Jedenfalls ist man sich über den Einfluss des Insulins auf den Purinstoffwechsel noch nicht im klaren. L. Kürti und G. Györgyi referierten, dass das Insulin eine wechselnde Wirkung auf die endogene Harnsäureausscheidung auszuüben scheine. Doch sei die Wirkung nur unbedeutend. G. Taubmann berichtete, dass während die Gesamtstickstoffwerte des Harns sich nicht aenderten, die Allantoinwerte deutliche Zunahme zeigten. Ich nahm mir bei dieser Unklarheit daher vor, den Einfluss des Insulins auf den Purinstoffwechsel möglichst sorgfältig und genau zu studieren. Da das Insulin zum Kohlenhydratstoffwechsel in inniger Beziehung steht, wurde bei dem Versuch auch ein Kombinationsversuch mit Insulin und Traubenzucker angestellt. Ich injizierte auch hypertonische 'Traubenzuckerlösung allein, und weil ich dabei ein interessantes Resultat gewonnen habe; will ich es hier mitreferieren. Die Untersuchungsmethode war fast dieselbe wie die bei meinen Untersuchungen über den Einfluss des Chininum hydrochloricum auf den Purinstoffwechsel beim experimentellen Hyperthyreoidismus. 
Die Resultate sind die folgenden :

1) Bei der subkutanen Injektion des Insulins $(3 \times 5$ Einheiten pro die 20 Minuten vor dem Essen) neigt der Gesamtstickstoff zur Verminderung. Der Purinbasen-Harnsäure-Stickstoff zeigt keine deutliche Veraenderung, der Allantoinstickstoff aber nimmt sowohl in der absoluten Menge als auch im Prozentsatz zum Gesamtstickstoff ab.

2) Bei der intravenösen Injektion der Traubenzuckerlösung (50 cem der $25 \%$ igen Lösung pro die) nimmt die Harnmenge zu und das spezifische Gewicht des Harns ab. Aber mit Rücksicht auf die hinzugefügte Wassermenge als Zuckerlösung kann man nicht behaupten, dass es durch die Injektion beim normalen Tier zur Diurese kommt.

Das Körpergewicht nimmt ein wenig zu und der Gesamtstickstoff ab, der Allantoinstickstoff aber beträchtlich zu und auch der Purinbasen-Harnsäure-Stickstoff ein wenig.

3) Bei der kombinierten Injektion von Insulin und hypertonischer Traubenzuckerlösıng neigen die Urinmenge und das spezifische Gewicht des Harns zu denselben Veränderungen wie bei einfacher Injektion der Traubenzuckerlösung. Der Gesamtstickstoff vermindert sich und der Purinbasen-Harnsäure-Stickstoff zeigt Neigung zur Verminderung hinsichtlich der absoluten und der relativen Menge. Der Allantoinstickstoff nimmt zu, aber geringgradiger als bei der einfachen Injektion von Traubenzuckerlösung.

4) Bei der Traubenzuckerdarreichung per os vermindert sich der Gesamtstickstoff. Der Purinbasen-Harnsäure-Stickstoff und der Allantoinsticksoff neigen zur Verminderung. Gleichzeitige subkutane Insulininjektion verstärkt diese Wirkung des per os gegebenen Traubenzuckers und vermindert auch den Prozentsatz von PurinbasenHarnsäure-Stickstoff und Allantoinstickstoff dem Gesamtstickstoff gegenüber.

Nach all dem obigen hemmt die subkutane Injektion einer geeigneten Menge Insulin den Stickstoffwechsel, besonders den Purinstoffwechsel. Auch die Darreichung von Traubenzucker per os hemmt hier.

- Die intravenöse Injektion von hypertonischer Traubenzuckerlösung 
führt zur Abnahme des Gesamtstickstoffs, aber zur Vermehrung der Purinkörper des Harns.

(Autoreferat)

\section{Ueber den Einfluss der Geschlechtsdrüsen auf die Hippursäuresynthese. 1. Mitteilung. Ueber den Einfluss der Hoden auf die Hippursäuresynthese.}

$$
\text { Von }
$$

Dr. T. Koyasako.

Aus der I. med. Klinik der Kaiserl. Universitaet zu Kyoto in Japan. Direktor: Prof. Dr. K. Tsuji.)

Um den Finfluss der Hoden auf die Hippursäuresynthese festzustellen, hat der Verfasser Versuche an erwachsenen männlichen Kaninchen angestellt, indem er ihnen die Hoden exstirpierte oder sie mit Hodensubstanz ( $0.5 \mathrm{~g}$ trockener Rinderhodensubstanz pro Kopf pro die) fütterte. Darauf untersuchte er die Verschiebung des Hippursäuregehalts im Harn.

Die Resultate waren die folgenden :-

1) Bei der Exstirpation der Hoden nimmt die Ausscheidung der Hippursäure im Harn ab.

2) Bei der Darreichung von Hodensubstanz nimmt die Ausscheidung der Hippursäure im Harn zu.

(Autoreferat)

\section{Ueber den Einfluss der Geschlechtsdrüsen auf die Hippursäuresynthese. II. Mitteilung. Ueber den Einfluss des Ovariums auf die Hippursäuresynthese.}

Von

Dr. 'T. Koyasako. 